\title{
Properties and Opioid Inhibition of Mesolimbic Dopamine Neurons Vary according to Target Location
}

\author{
Christopher P. Ford, ${ }^{1}$ Gregory P. Mark, ${ }^{2}$ and John T. Williams ${ }^{1}$ \\ ${ }^{1}$ Vollum Institute, L474, and 2Department of Behavioral Neuroscience, Oregon Health and Science University, Portland, Oregon 97239
}

The mesolimbic dopamine system, which mediates the rewarding properties of nearly all drugs of abuse, originates in the ventral tegmental area (VTA) and sends major projections to both the nucleus accumbens (NAc) and the basolateral amygdala (BLA). To address whether differences occur between neurons that project to these separate areas, retrograde microspheres were injected to either the BLA or the NAc of DBA/2J mice. Whole-cell recordings were made from labeled VTA dopamine neurons. We found that identified neurons that projected to the BLA and NAc originated within different quadrants of the VTA with neither group exhibiting large-amplitude h-currents. Neurons that projected to the NAc exhibited a greater outward current in response to the $\kappa$-opioid agonist $(5 \alpha, 7 \alpha, 8 \alpha)-(+)-N$-methyl$N$-[7-(pyrrolidinyl)-1-oxaspiro [4,5]dec-8-yl]-benzeneacetamide (U69593; $200 \mathrm{nM})$, whereas neurons that projected to the BLA exhibited greater inhibition to the $\mu / \delta$ opioid agonist $\left[\mathrm{Met}^{5}\right]$ enkephalin (ME; $3 \mu \mathrm{M}$ ). In addition, we found that the presynaptic inhibition of GABAergic transmission at both $\mathrm{GABA}_{\mathrm{A}}$ and $\mathrm{GABA}_{\mathrm{B}}$ receptors was differentially regulated by $\mathrm{U} 69593$ between the two groups. When dopamine IPSCs were examined, U69593 caused a greater inhibition in NAc- than BLA-projecting neurons. ME had no effect on either. Finally, the regulation of extracellular dopamine by dopamine uptake transporters was equal across the VTA. These results suggest that opioids differentially inhibit mesolimbic neurons depending on their target projections. Identifying the properties of projecting mesolimbic VTA dopamine neurons is crucial to understanding the action of drugs of abuse.

Key words: morphine; withdrawal; $\kappa$-opioid; $\mu$-opioid; ventral tegmental area; retrograde labeling

\section{Introduction}

The mesolimbic dopamine (DA) system originates from neurons within the ventral tegmental area (VTA) and projects to limbic structures that include the nucleus accumbens (NAc) and the basolateral amygdala (BLA) (Albanese and Minciacchi, 1983). Dopamine projections to these target areas mediate both natural rewards and the rewarding aspects of drugs of abuse (Koob, 1992; White, 1996; Wise, 1996a,b). Both target regions mediate components of drug-seeking in animal models of addiction (Everitt et al., 2001). Some components, such as drug-primed reinstatement and second-order conditioning, may overlap in the BLA (Whitelaw et al., 1996; See et al., 2001) and the NAc (Bachtell et al., 2005). In other aspects (appetitive conditioning and withdrawal), amygdaloid regions may have a more specialized role (Hatfield et al., 1996; Frenois et al., 2005) than the medial NAc, which mediates primary rewarding properties of drugs (Koob, 1992; Ikemoto and Panksepp, 1999).

Within the VTA, neurons are classified as primary, secondary, and tertiary (Grace and Onn, 1989; Johnson and North, 1992b; Cameron et al., 1997; Ungless et al., 2004). Primary neurons con-

Received 0ct. 11, 2005; revised Jan. 31, 2006; accepted Feb. 2, 2006.

This work was supported by National Institutes of Health Grants DA08163 and DA04523 (J.T.W.) and DA014639 (G.P.M.). C.P.F. is a Wyeth fellow of the Life Sciences Research Foundation and a fellow of the Alberta Heritage Foundation for Medical Research. We thank Stephanie Gantz for help with immunochemistry and confocal microscopy.

Correspondence should be addressed to John T. Williams, Vollum Institute, L474, Oregon Health and Science University, 3181 Southwest Sam Jackson Park Road, Portland, OR 97239. E-mail: williamj@0HSU.edu. DOI:10.1523/JNEUROSCI.4331-05.2006

Copyright $\odot 2006$ Society for Neuroscience $\quad$ 0270-6474/06/262788-10\$15.00/0 tain tyrosine hydroxylase (TH) and are the dopaminergic output neurons of the VTA. Both primary and tertiary neurons exhibit a hyperpolarization-activated cation current $\left(I_{\mathrm{h}}\right)$, pace maker firing, and long-duration action potentials (APs). Secondary cells are GABAergic. They do not possess an $I_{\mathrm{h}}$ and exhibit fast firing with narrow APs. Both $\mu$-opioid receptors (MORs) and $\kappa$-opioid receptors (KORs) are expressed within the VTA. KOR agonists hyperpolarize primary and tertiary cells (Margolis et al., 2003). Alternatively, MOR agonists hyperpolarize secondary and tertiary cells (Johnson and North, 1992b; Cameron et al., 1997). By inhibiting GABA release from secondary interneurons, MOR agonists activate dopamine neurons (Gysling and Wang, 1983; Johnson and North, 1992a). This opposing effect of the $\mu$ and $\kappa$ systems on DA cell activity has been noted in multiple brain regions (Pan, 1998). These systems also exert opposing behavioral actions, because in vivo infusions of MOR agonists into the VTA elicits place preference, whereas KOR agonists elicits place aversion (Phillips and LePiane, 1980; Bals-Kubik et al., 1993).

Although it is known that the VTA sends dopaminergic projections to mesolimbic target areas and these inputs are central to behaviors mediated by these nuclei, little is known of the physiological properties of the projecting VTA dopamine neurons themselves. We set out to examine the properties of two populations of mesolimbic neurons: those that project to the BLA and those projecting to the NAc. We hypothesized that because these target areas serve different functions, the neurons projecting to these areas would exhibit different properties. Dopamine neuron activity is tightly regulated by a variety of inhibitory inputs. These 
inputs are acutely inhibited by opioids but are also altered during withdrawal from chronic opioid use (Williams et al., 2001). Because opioids exert direct effects on mesolimbic neurons within the VTA, as well as altering the activity of their inhibitory presynaptic inputs, we examined whether differences in the effects of opioids existed between these two neuronal populations.

\section{Materials and Methods}

Intracerebral microinjections. Male and female 6- to 8-week-old DBA/2J mice (The Jackson Laboratory, Bar Harbor, ME) were used in all experiments. Mice were anesthetized with an intraperitoneal injection of ketamine $(30 \mathrm{mg} / \mathrm{cc})$, xylazine $(2.9 \mathrm{mg} / \mathrm{cc})$, and acepromazine $(0.6 \mathrm{mg} / \mathrm{cc})$. With use of a stereotaxic apparatus (Kopf Instruments, Tajunga, CA), fluorescent microspheres (200 nl; diameter, $0.04 \mu \mathrm{m}$; 488/560 EX/EM; Invitrogen, San Diego, CA) were injected bilaterally (over 4-6 min) into either the shell of the NAc [from bregma (in $\mathrm{mm}$ ): +1.5 anteroposterior, \pm 0.65 lateral, -5.2 ventral] or the BLA [from bregma (in $\mathrm{mm}$ ): -1.35 anteroposterior, \pm 3.05 lateral, -5.9 ventral]. Acute brain slices were prepared from mice that received either NAc or BLA injections after allowing 2-5 d for retrograde transport of the microspheres. Animals were excluded from the study if more than a minor portion of the injection occurred outside of the area of interest. Special care was taken during the injection and removal of the injection syringe to minimize spread of tracer dorsally along the injection tract into striatal structures.

Slice preparation and recording. Midbrain horizontal slices $(220 \mu \mathrm{m})$ were cut, as described previously (Williams et al., 1984), in ice-cold physiological saline solution containing (in $\mathrm{mm}$ ) $126 \mathrm{NaCl}, 2.5 \mathrm{KCl}, 1.2$ $\mathrm{MgCl}_{2}, 2.4 \mathrm{CaCl}_{2}, 1.4 \mathrm{NaH}_{2} \mathrm{PO}_{4}, 25 \mathrm{NaHCO}_{3}, 11$ D-glucose, and 0.4 ascorbate using a vibratome (Leica, Nussloch, Germany). Slices were incubated in warm $\left(35^{\circ} \mathrm{C}\right) 95 \mathrm{O}_{2} / 5 \% \mathrm{CO}_{2}$ oxygenated saline containing $10 \mu \mathrm{M}(+)$-5-methyl-10,11-dihydro-5H-dibenzo [a,d] cyclohepten5,10-imine maleate (MK-801) for at least $30 \mathrm{~min}$ and transferred to a chamber that was constantly perfused $(1.5 \mathrm{ml} / \mathrm{min})$ with saline $\left(35^{\circ} \mathrm{C}\right)$.

VTA DA neurons were visualized using "Dodt"-type gradient contrast infrared optics (Dodt et al., 2002). With the use of fluorescent microscopy, microspheres identified DA neurons that projected to either the NAc or the BLA. Physiological identification of DA neurons was based on the presence of spontaneous pacemaker firing $(1-5 \mathrm{~Hz})$ and an AP width of $>1.2 \mathrm{~ms}$. Action potential width was defined as the time from the initial inward current to the peak of the outward current when measured in cell-attached voltage-clamp mode. Only DA neurons within the VTA [within or medial to the medial lemniscus; medial to the medial terminal nucleus of the accessory optic tract (MT)] were included within this study.

Whole-cell recordings were made with $1.8-2.5 \mathrm{M} \Omega$ pipettes using an Axopatch 200A amplifier (Molecular Devices, Foster City, CA). Cells were voltage clamped at $-60 \mathrm{mV}$. Series resistance, monitored throughout the experiment, ranged from 3 to $15 \mathrm{M} \Omega$, and was compensated by $80 \%$. All currents were recorded at $10 \mathrm{kHz}$ and filtered at $5 \mathrm{kHz}$. GABA IPSCs were recorded with pipettes filled with the following (in $\mathrm{mm}$ ): $57 \mathrm{KCl}, 57 \mathrm{~K}$ methylsulphate, $20 \mathrm{NaCl}, 1.5 \mathrm{MgCl}_{2}, 5$ HEPES (K), 0.1 EGTA, 2 ATP, 0.3 GTP, and 10 phosphocreatine, $\mathrm{pH} 7.3,270 \mathrm{mOsm}$. IPSCs were evoked with bipolar electrodes placed $\sim 300 \mu \mathrm{m}$ caudal from the recorded neuron (duration, $0.1 \mathrm{~ms}$ ) every $20 \mathrm{~s}$ and were pharmacologically isolated with 6,7dinitroquinoxaline-2,3(1H,4H)-dione (DNQX; $10 \mu \mathrm{M})$, strychnine $(1 \mu \mathrm{M})$, and MK-801 $(10 \mu \mathrm{M}) . \mathrm{GABA}_{\mathrm{B}}$ and $\mathrm{D}_{2}$ IPSCs were recorded with pipettes filled with the following (in mM): $115 \mathrm{~K}$-methylsulphate, $20 \mathrm{NaCl}, 1.5 \mathrm{MgCl}_{2}$, 5 HEPES (K), 0.1 EGTA, 2 ATP, 0.3 GTP, and 10 phosphocreatine, $\mathrm{pH} 7.3$, $270 \mathrm{mOsm}$. IPSCs were evoked with monopolar glass electrodes placed $\sim 50-100 \mu \mathrm{m}$ caudal to the recorded neuron by a train of five pulses (dura-

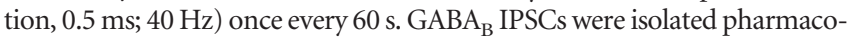
logically with picrotoxin $(100 \mu \mathrm{M}), \mathrm{DNQX}(10 \mu \mathrm{M})$, sulpiride $(300 \mu \mathrm{M})$, and MK-801 $(10 \mu \mathrm{M})$. $\mathrm{D}_{2}$ IPSCs were isolated pharmacologically with picrotoxin $(100 \mu \mathrm{M})$, DNQX $(10 \mu \mathrm{M})$, [3-[1-(R)-[(3-cyclohexylmethyl)hydroxyphosphinyl]-2-(S)-hydroxy-propyl]amino] ethyl-benzoic acid (CGP 56999a) $(100 \mathrm{nM})$, and MK-801 $(10 \mu \mathrm{M}) . \mathrm{D}_{2}$ ionotphoretic currents were elicited with a thin-walled inotophoretic microelectrode $(\sim 100 \mathrm{M} \Omega)$, filled with $1 \mathrm{M}$ dopamine and placed $\sim 10-20 \mu \mathrm{m}$ from the cell. A retention current of approximately $-3 \mathrm{nA}$ was applied to prevent passive leakage of dopamine.

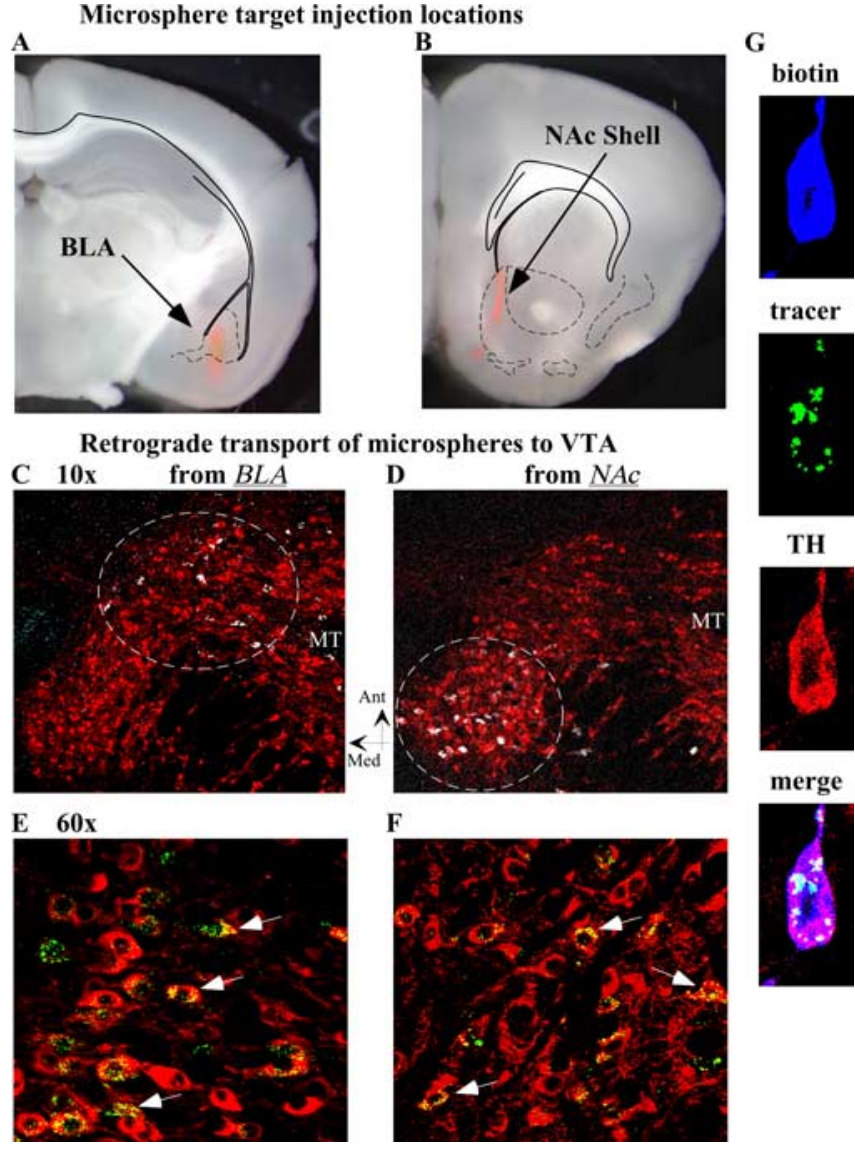

Figure 1. VTA neurons that project to the BLA and the NAc originate from distinct anatomical locations within the VTA. $A, B$, Bright-field images identifying the anatomical location of injection sites of retrograde tracers into either the BLA or the NAc [overlay adapted from (Paxinos and Franklin (2001)]. C, D, Horizontal confocal sections $(10 \times)$ imaged after staining for tyrosine hydroxylase (red) to identify DA neurons from mice in which microspheres (overlaid in white) were retrogradely transported from the BLA (C) or NAC (D). Ant, Anterior; Med, medial. $\boldsymbol{E}, \boldsymbol{F}$, High-power $60 \times$ single-plane confocal sections $(0.1 \mu \mathrm{m})$ illustrating the presence of microspheres (green) and DA neurons stained for $\mathrm{TH}$ (red). The arrows illustrate representative neurons in which yellow indicates the colocalization of microspheres and TH. $G$, Example of a neurobiotin-filled neuron from a mouse in which tracer was injected into the BLA. Triple staining for neurobiotin, tracer, and TH confirms that this recorded BLA-projecting neuron was DAergic.

Dopamine was ejected as a cation with a single pulse (20-150 nA; 25-100 ms).

Immunohistochemistry. Mice were anesthetized with 2,2,2tribromoethanol (Avertin; Sigma, St. Louis, MO) and transcardially perfused with $5 \%$ sucrose/PBS, followed by $4 \%$ paraformaldehyde in PBS. The brains were removed, postfixed overnight at $4^{\circ} \mathrm{C}$, and horizontally sliced in $50 \mu \mathrm{m}$ sections. Free-floating sections were washed three times in KPBS with $0.3 \%$ Triton-X (KPBS-T), incubated in KPBS-T with $5 \%$ normal goat serum for $1 \mathrm{~h}$, then incubated overnight with primary anti-TH (1:10,000; IncStar, Stillwater, MN). Sections were rinsed three times in KPBS and incubated for $2 \mathrm{~h}$ in Alexa-647-conjugated goat antimouse secondary antibody (1:1000; Invitrogen). Sections were rinsed with KPBS, mounted with anti-fading gel mount (Biomeda, Foster City, $\mathrm{CA}$ ), and visualized with laser scanning confocal microscopy.

To test for colocalization of filled neurons with TH, cells within 220 $\mu \mathrm{m}$ slices were patched and filled with $0.3 \%$ neurobiotin (Vector Laboratories, Burlingame, CA). Slices were fixed overnight in 4\% paraformaldehyde in PBS, washed with $0.3 \%$ KPBS-T, incubated in KPBS-T with $5 \%$ normal goat serum for $1 \mathrm{~h}$, and then incubated overnight with primary anti-TH (1:10,000; IncStar). Slices were rinsed three times in KPBS and incubated for $2 \mathrm{~h}$ in Alexa-488-conjugated goat anti-mouse secondary antibody (1:1000; Invitrogen). Slices were then incubated for $1 \mathrm{~h}$ in 
Alexa-568-conjugated streptavidin (1:1000; Invitrogen), rinsed, mounted, and visualized with a laser scanning confocal microscope.

Data analysis. Values are given as means \pm SEM. In all experiments, $p<0.05$ was considered a significant difference. Statistical significance was assessed using either a Student's unpaired $t$ test or one-way ANOVA (Bonferonni's post hoc analysis).

\section{Results}

Anatomy of projecting mesolimbic

VTA neurons

Fluorescent microspheres injected into either the NAc shell (NAc) or the BLA were retrogradely transported to neuronal cell bodies of the VTA. Because DA neurons of the substantia nigra compacta (SNc) project to striatal structures lying dorsal to the NAc and BLA, care was taken to include in this study only animals in which injections were within the appropriate target area. Figure 1, $A$ and $B$, illustrates typical injection sites into the BLA and the NAc from two separate mice. No labeling was observed in the VTA when microinjections were made dorsal to either the NAc or BLA (data not shown).

To determine the anatomical location of projecting DA neurons, horizontal midbrain slices from BLA- and NAc-injected animals were examined for $\mathrm{TH}$ immunoreactivity. In mice receiving injections into the BLA, fluorescent microspheres were found to colocalize with $\mathrm{TH}$-positive neurons in the anterior/lateral portions of the VTA (Fig. 1C). In contrast, injection of tracer into the NAc led to fluorescent microsphere colocalization with $\mathrm{TH}$-positive neurons in the posterior/medial VTA (Fig. $1 D)$. Thus, the NAc and BLA receive projection from distinct anatomical locations within the VTA. High-power $(60 \times)$ images further illustrating the presence of retrograde transported beads from either the BLA or the NAc in VTA DA neurons are shown in Figure 1, $E$ and $F$. It can be seen that the majority of tracer-labeled neurons that projected to both the BLA and the NAc stained positively for the presence of TH. Because of the small volumes of tracer used, only low numbers $(20-150)$ of labeled cells occurred in each slice. To further examine the neurochemical identity of tracer-labeled neurons, we filled tracer-labeled neurons with neurobiotin. In 12 of 13 cells from slices from animals in which injections of tracer were made into the BLA, the presence of $\mathrm{TH}$ colocalized with both tracer and neurobiotin. An example of such a cell is illustrated in Figure $1 G$. These anatomical findings suggest that with the use of fluorescent mi-
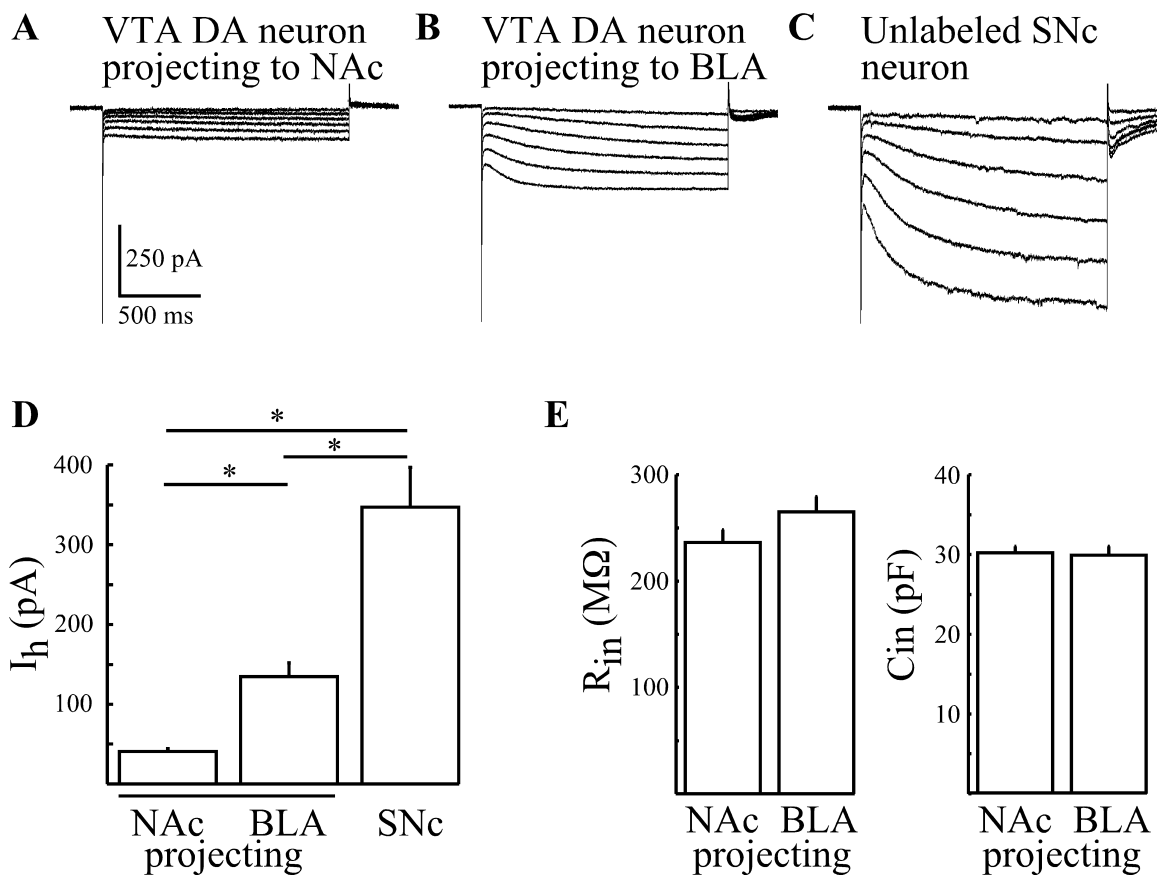

$\mathbf{E}$
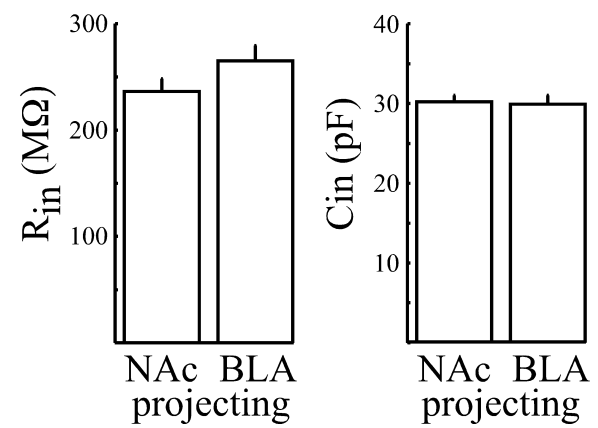

Figure 2. Amplitude of $I_{\mathrm{h}}$ is different among BLA- and NAc-projecting VTA neurons and SNc neurons. $\boldsymbol{A}-\boldsymbol{C}$, Typical families of whole-cell currents evoked by $-10 \mathrm{mV}$ square-wave step pulses from $V_{\mathrm{h}}$ of -60 to $-120 \mathrm{mV}$ recorded from NAc- $(\boldsymbol{A})$, and BLA$(B)$ projecting and unlabeled SNc $(\boldsymbol{C})$ neurons. D, Summary of observed mean $I_{\mathrm{h}}$ amplitudes from NAc-projecting $(n=45)$, BLA-projecting $(n=47)$, and unlabeled SNc neurons $(n=11)$. $\boldsymbol{E}$, Summary of observed input resistances and capacitances from BLA- and NAc-projecting neurons. Error bars signify SEM. * ${ }^{*}$ signifies significance at $p<0.05$.
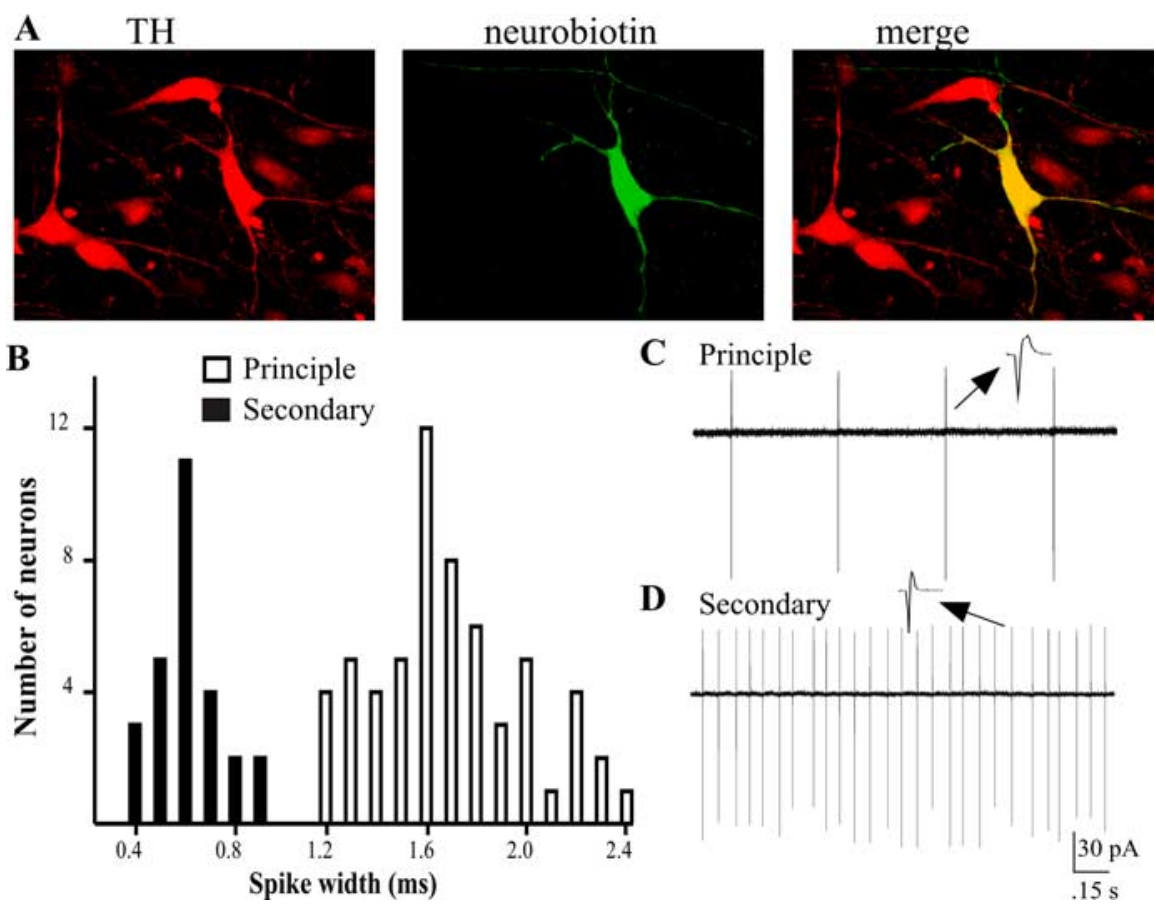

Figure 3. Action potentials wider than 1.2 ms are a marker of principle DA neurons. $\boldsymbol{A}$, Stacked ( $0.1 \mu \mathrm{m}$ section, $1 \mu \mathrm{m}$ step, 10 stacked images) horizontal confocal image of a neuron that was filled with $0.3 \%$ neurobiotin. Neurobiotin was visualized by treating slices with Alexa-568-conjugated streptavidin (green). Neurons were also stained for TH (red). The overlay illustrates the colocalization (yellow) of the filled cell with TH. $\boldsymbol{B}$, Histogram illustrating the spike width distribution of microsphere-labeled VTA DA neurons and control, unlabeled secondary neurons. Note the lack of overlap between the two populations of neurons. $C, D$, Cell-attached extracellularly recorded APs recorded from the principle $D A$ neuron illustrated in $A$ and an unlabeled control secondary neuron $(D)$. 


\section{A NAc projecting}

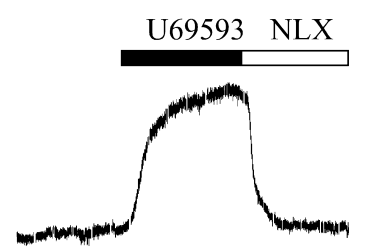

$\mathrm{ME}$
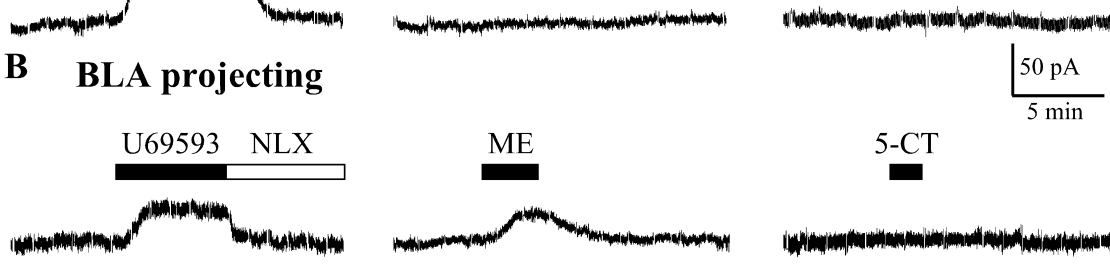

C

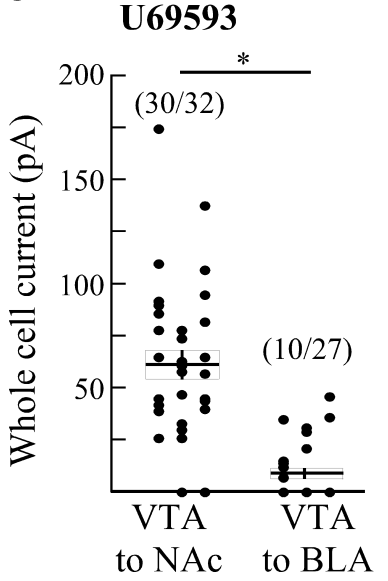

D

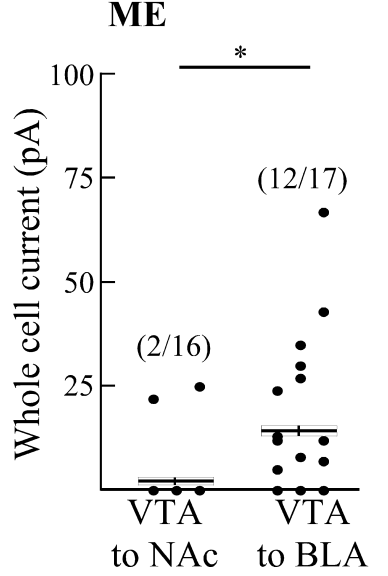

$\mathbf{E}$

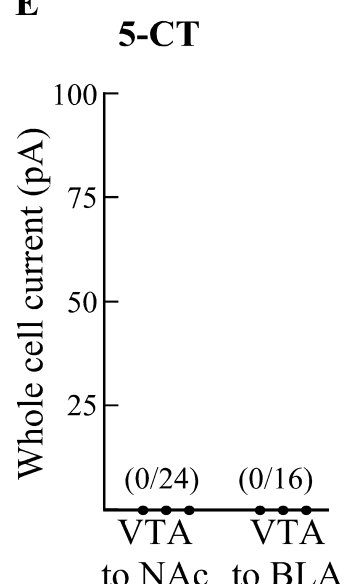

Figure 4. Opioid inhibition of mesolimbic VTA neurons is dependent on target location. $A, B$, Whole-cell currents produced in representative NAc- $(\boldsymbol{A})$ and BLA- $(\boldsymbol{B})$ projecting neurons in response to the KOR agonist U69593 $(200 \mathrm{nM})$, the M/DOR agonist ME (3 $\mu \mathrm{m})$, and the $5-\mathrm{HT}_{1}$ agonist 5-CT (100 nm). The nonspecific opioid receptor antagonist naloxone (NLX; $\left.1 \mu \mathrm{m}\right)$ was used to reverse the effect caused by U69593. $\boldsymbol{C}-\boldsymbol{E}$, Scatter plots illustrating both the peak-amplitude whole-cell currents from NAC- and BLAprojecting neurons in response to U69593 (200 nм; $\boldsymbol{C}$, ME (3 $\mu \mathrm{M} ; \boldsymbol{D})$, and 5-CT (100 nм; $\boldsymbol{E})$. The numbers in parentheses signify the proportion of total cells recorded that responded to drug application with a measurable outward current. The box and whisker plot illustrates the mean \pm SEM. Note the opposing actions of the KOR and M/DOR agonists on BLA- and NAc-projecting cells. 5-CT failed to produce an outward current in all recorded neurons. ${ }^{*}$ signifies significance at $p<0.05$.

crospheres as retrograde tracers, the majority of mesolimbic VTA-projecting neurons identified with this technique contain $\mathrm{TH}$.

\section{Electrophysiological properties of NAc- and BLA-projecting DA neurons}

Because BLA- and NAc-projecting neurons occupied distinct anatomical locations within the VTA, we reasoned that intrinsic electrophysiological properties might also vary between these two groups of neurons. To test this hypothesis, whole-cell voltage-clamp recordings were made from labeled neurons in brain slices under fluorescent microscopy. Cells were electrically identified as DA neurons by the presence of extracellularly recorded AP widths of $\geq 1.2 \mathrm{~ms}$. Initial experiments examined $I_{\mathrm{h}}$ amplitudes from labeled NAc- and BLA-projecting VTA DA neurons. To activate $I_{\mathrm{h}}$, neurons were hyperpolarized with $1.5 \mathrm{~s}$ steps to $-120 \mathrm{mV}$ from a holding potential $\left(V_{\mathrm{h}}\right)$ of $-60 \mathrm{mV}$. DA neurons projecting to the NAc exhibited significantly smaller $I_{\mathrm{h}}$ than BLA-projecting DA neurons ( $41 \pm 4 \mathrm{pA}, n=47$ vs $135 \pm 17$ pA, $n=45$; $p<0.05$ ) (Fig. 2, compare $A$ and $B, D$ ). For comparison, unlabeled $\mathrm{SNc}$ neurons exhibited a pronounced $I_{\mathrm{h}}$ that was

significantly larger than those recorded from labeled VTA DA neurons $(347 \pm 49$ $\mathrm{pA} ; n=11 ; p<0.05$ vs BLA- and NAcprojecting cells) (Fig. 2C,D). Thus, labeled projecting NAc, BLA, and unlabeled SNc DA cells exhibit significantly different $I_{\mathrm{h}}$ amplitudes. Furthermore, $I_{\mathrm{h}}$ may not be an appropriate marker of these mesolimbic neurons.

To further characterize the electrophysiological properties of projecting neurons, input resistance $\left(R_{\mathrm{in}}\right)$ and capacitance $\left(C_{\text {in }}\right)$ were also measured. BLA- and NAc-projecting VTA DA neurons exhibited similar values (NAc: $30 \pm 1 \mathrm{pF}, 236 \pm$ $12 \mathrm{M} \Omega, n=60$; BLA: $30 \pm 1 \mathrm{pF}, 265 \pm 14$ $\mathrm{M} \Omega, n=65 ; p>0.05$ ) (Fig. $2 E$ ), suggesting that whereas differences occur in $I_{\mathrm{h}}$, other intrinsic electrophysiological properties are conserved.

In vivo recordings from the rat have proposed that spike width may be an accurate determinate of VTA cellular identity, with principle DA neurons possessing APs significantly wider than nondopaminergic neurons (Ungless et al., 2004). In cellattached mode, the width of extracellularly recorded APs in all bead labeled neurons was $\geq 1.2 \mathrm{~ms}$ (mean width, $1.7 \pm 0.1 \mathrm{~ms}$; $n=60$ ) (Fig. 3B). This value clearly separated DA neurons from a second population of neurons, which exhibited AP widths of $\leq 0.9 \mathrm{~ms}$ (mean width, $0.6 \pm$ $0.05 ; n=27 ; p<0.05$ ) (Fig. $3 B$ ). This second population was presumed to be secondary GABAergic neurons because of their narrow-width APs, high frequency firing $(>10 \mathrm{~Hz})$, inhibition by bath application of the $\mu / \delta$ agonist [Met ${ }^{5}$ ] enkephalin (ME; $3 \mu \mathrm{M})$, and lack inhibition by exogenously applied DA (10 $\mu \mathrm{M})$ (Johnson and North, 1992a,b; Cameron et al., 1997). Secondary cells were also clearly distinguishable from bead-labeled DA neurons by their passive membrane properties $\left(R_{\mathrm{in}}, 1932 \pm 155 \mathrm{M} \Omega\right.$; $C_{\mathrm{in}}$, $17 \pm 1 \mathrm{pF} ; n=39 ; p<0.05$; data not shown). To confirm that our electrophysiological criteria for identifying DA neurons matched their neurochemical identity, neurons were filled with $0.3 \%$ neurobiotin and after recording stained for the presence of TH. In 11 of 11 neurons, the presence of neurobiotin colocalized with $\mathrm{TH}$. A representative neuron is illustrated in Figure $3 \mathrm{~A}$. All of these 11 cells recorded and filled with neurobiotin possessed AP widths $\geq 1.2 \mathrm{~ms}$. AP widths matched the range of NAc and BLA projecting bead-labeled neurons (mean width, $1.5 \pm 0.05 \mathrm{~ms} ; n=11$; $p>0.05)$. Furthermore, these filled cells exhibited passive membrane properties that closely matched tracer-labeled BLA- and NAc-projecting neurons $\left(R_{\mathrm{in}}, 249 \pm 12 \mathrm{M} \Omega ; C_{\mathrm{in}}, 30 \pm 1 \mathrm{pF} ; n=\right.$ $11 ; p>0.05$; data not shown). The firing of the filled neuron shown in Figure $3 A$ is illustrated in Figure $3 C$. These observations indicate that the physiological properties of bead-labeled VTA neurons that projected to either the BLA or the NAc correspond to principle DA neurons. 
Postsynaptic inhibition by opioids Because MOR and KOR agonists produce opposing effects with the VTA, we tested whether BLA- and NAc-projecting neurons would be differentially inhibited by these two classes of opioids. The KOR agonist $(5 \alpha, 7 \alpha, 8 \alpha)-(+)-N$-methyl- $N$-[7-(pyrrolidinyl)-1-oxaspiro [4,5] dec-8-yl]-benzeneacetamide (U69593) inhibits primary and tertiary VTA neurons by activating Gprotein-coupled inwardly rectifying $\mathrm{K}^{+}$ (GIRK) channels (Margolis et al., 2003). We found that U69593 (200 nM) produced an outward current of $61 \pm 5 \mathrm{pA}(n=32)$ in NAc-projecting neurons, which was significantly greater than the current produced in BLA-projecting neurons $(9 \pm 3$ $\mathrm{pA} ; n=27 ; p<0.05$ ) (Fig. 4C). Representative traces illustrating the effect of U69593 are shown in Figure $4, A$ and $B$. Physiological and anatomical evidence demonstrates that MORs are also present on a small population of VTA DA neurons (Cameron et al., 1997; Garzon and Pickel, 2001). To determine whether these cells project to the BLA and the NAc, we measured the whole-cell current induced by the reversible $\mu / \delta$-opioid receptor (M/ DOR) agonist ME. Opposite to the effect of U69593, neurons projecting to the NAc exhibited a mean outward current in response to bath-applied ME (3 $\mu \mathrm{M} ; 2.1 \pm$ $1.5 \mathrm{pA} ; n=16$ ), which was significantly less than that produced in BLA-projecting cells (14 \pm 4 pA; $n=17 ; p<0.05)$ (Fig. $4 D)$. Typical current traces are illustrated in Figure $4, A$ and $B$. These results show that NAc- and BLA-projecting VTA DA neurons show differential sensitivities to opioids.

Tertiary cells are also directly inhibited by serotonin (5-HT) (Cameron et al., 1997). We hypothesized that because 71\% (12 of 17) of BLA-projecting neurons, but only 13\% (2 of 16) of NAcprojecting neurons, were inhibited by ME (Fig. 3D), a similar percentage would be inhibited by 5 -HT receptor (5-HT-R) activation. Surprisingly, application of the high-affinity $5-\mathrm{HT}_{1}$ agonist 5-carboxamidotryptamine (5-CT; $100 \mathrm{~nm}$ ) failed to produce a current in any recorded BLA- or NAc-projecting neuron (Fig. $4 A, B, E)$. This concentration was highly effective on presynaptic inputs to these cells (see below), implying that a sufficiently high concentration was used to activate $5-\mathrm{HT}_{1}$ receptors in the slice preparation. Thus, in the mouse, both BLA- and NAc-projecting VTA DA neurons are not directly inhibited by $5-\mathrm{HT}_{1}-\mathrm{R}$ activation.

Because we found that mesolimbic projecting neurons responded to ME but not 5-CT, we attempted to confirm the neurochemical identity of these neurons to ensure that they were DA cells. Because we found that the majority of cells that project to the BLA (but not the NAc) responded to ME, we examined the responses of these BLA-projecting tracer-labeled cells to $\mathrm{ME}$ while filling those neurons with neurobiotin. We found that of nine BLA-projecting neurons that were filled with neurobiotin and challenged with $\mathrm{ME}$, five $\mathrm{TH}(+)$ cells responded $(22 \pm 5 \mathrm{pA}$; data not shown), three $\mathrm{TH}(+)$ cells did not respond, and one $\mathrm{TH}(-)$ cell responded. An example of a triple-labeled (neurobiotin/tracer/TH) BLA-projecting neuron in which ME induced a $10 \mathrm{pA}$ outward current is illustrated in Figure 1G. These observations suggest that under the current experimental conditions, the vast majority of tracer-labeled neurons were DA cells.

\section{Inhibition of synaptic transmission}

Opioid inhibition of GABAergic transmission

Both BLA- and NAc-projecting neurons exhibited different postsynaptic responses to opioids, leading us to hypothesize that the inhibition of presynaptic inputs would also vary between these two groups. We initially examined GABAergic transmission. Separate GABA releasing terminals are believed to mediate $\mathrm{GABA}_{\mathrm{A}}$ and $\mathrm{GABA}_{\mathrm{B}}$ inputs to DA neurons of the VTA, with both being sensitive to opioids (Gysling and Wang, 1983; Johnson and North, 1992a; Johnson et al., 1992; Sugita et al., 1992; Cameron and Williams, 1993; Bonci and Williams, 1997; Shoji et al., 1999).

Pharmacologically isolated $\mathrm{GABA}_{\mathrm{A}}$ IPSCs were inward when evoked from a $V_{\mathrm{h}}$ of $-60 \mathrm{mV}$ (Fig. 5) and were completely blocked by picrotoxin ( $100 \mu \mathrm{M}$; data not shown). Application of U69593 (200 nM) inhibited BLA-projecting IPSCs by $34 \pm 6 \%$ $(n=8)$. This was greater than the inhibition of NAc-projecting IPSCs $(8 \pm 6 \% ; n=9 ; p<0.05)$ (Fig. $5 A)$. Inhibition of $\mathrm{GABA}_{\mathrm{A}}$ 


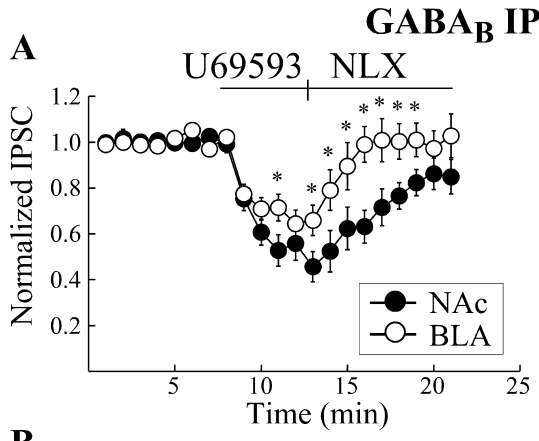

\section{GABA $_{B}$ IPSCs}
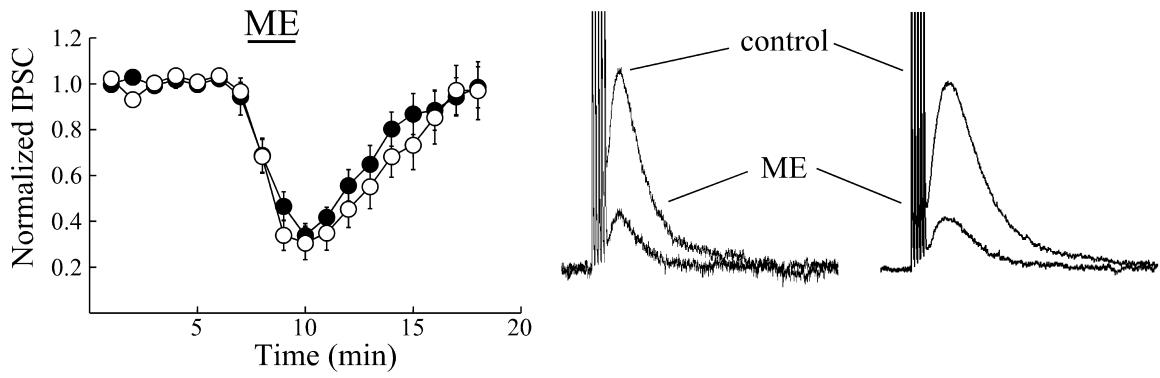

C
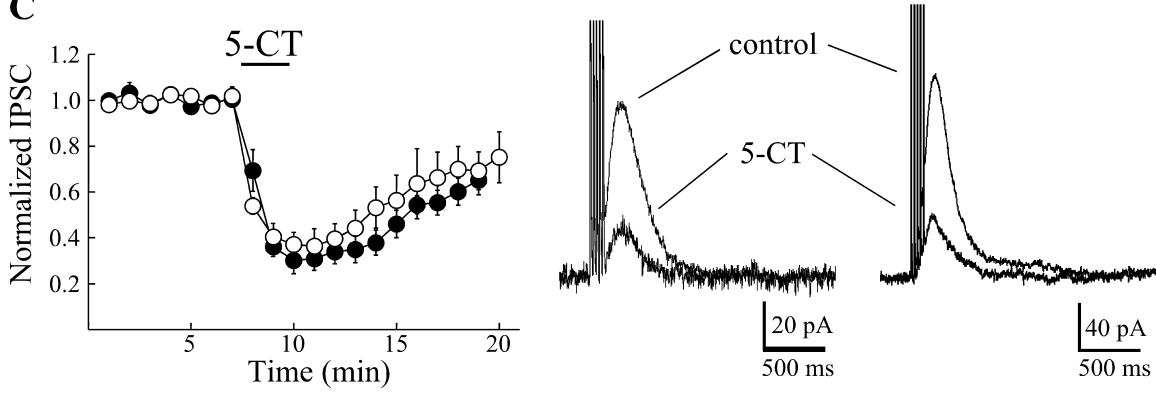

Figure 6. Inhibition of GABA ${ }_{B}$ IPSCs by opioids and 5-CT from identified BLA- and NAc-projecting neurons. A-C, Normalized summary data and typical recordings of $\mathrm{ABA}_{B}$ IPSC sillustrating the effects of U69593 (200 nM; $\left.\boldsymbol{A}\right), \mathrm{ME}(3 \mu \mathrm{M} ; \boldsymbol{B})$, and 5-CT (100 nM; C) on BLA- $(\bigcirc)$ and NAC- $(-)$ projecting VTA neurons $(n=6-8)$. Illustrated GABA $A_{B}$ IPSCs are the averages of two to four traces before and during drug application. IPSCs were evoked with monopolar glass electrodes by a train of five pulses (duration, $0.5 \mathrm{~ms}$; $40 \mathrm{~Hz}$ ) every $60 \mathrm{~s}$. The calibration in the middle panel of Capplies to all traces from NAc-projecting cells; the calibration in the right panel of $C$ applies to all traces from BLA-projecting cells. Error bars indicate SEM. * signifies significance at $p<0.05$. NLX, Naloxone.

currents by $\mathrm{ME}(3 \mu \mathrm{M})$ was similar for cells projecting to both the $\mathrm{BLA}(45 \pm 7 \% ; n=10)$ and the NAc $(49 \pm 7 \% ; n=7 ; p>0.05)$ (Fig. 5B).

The release of GABA that mediates $\mathrm{GABA}_{\mathrm{B}}$ IPSCs is also sensitive to both MOR and KOR opioid agonists (Shoji et al., 1999). A train of stimuli was used to evoke a slow IPSC (Fig. 6), which was sensitive to the $\mathrm{GABA}_{\mathrm{B}}$ receptor antagonist CGP 56999a (100 nM) (data not shown). Unlike GABA IPSCs, GABA $_{B}$ IPSCs recorded from neurons that projected to the NAc showed greater inhibition with U69593 (200 nM; $46 \pm 8 \%$ inhibition; $n=8$ ) than those that projected to the BLA $(26 \pm 8 \%$ inhibition; $n=7 ; p<$

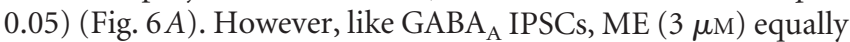
inhibited BLA- $(70 \pm 7 \%$ inhibition; $n=7)$ and NAc- $(66 \pm 6 \%$ inhibition; $n=8, p>0.05$ ) projecting neurons (Fig. $6 B$ ).

Thus, M/DORs equally inhibit GABAergic transmission onto DA neurons projecting to the BLA and the NAc. This is not the case for KORs. $\mathrm{GABA}_{\mathrm{A}}$ inputs are more sensitive on BLAprojecting neurons, whereas $\mathrm{GABA}_{\mathrm{B}}$ inputs are more sensitive on NAc-projecting neurons.

\section{5-HT inhibition of GABAergic transmission}

In the rat and guinea pig, 5-HT causes a potent inhibition of the $\mathrm{GABA}_{\mathrm{B}}$ IPSP but has no effect on the GABA $\mathrm{APSPs}$ (Sugita et al.,
1992). We examined 5-HT-R stimulation to see whether it would inhibit the $\mathrm{GABA}_{\mathrm{B}}$ IPSC from BLA- and NAc-projecting neurons. Application of 5-CT (100 nM) equally inhibited $\mathrm{GABA}_{\mathrm{B}}$ IPSCs from both the BLA- $(63 \pm 6 \%$ inhibition; $n=6)$ and NAc- $(70 \pm 5 \% ; n=7 ; p>0.05)$ projecting VTA DA neurons (Fig. 6C). Surprisingly, 5-CT (100 nM) was also able to effectively inhibit $\mathrm{GABA}_{\mathrm{A}}$ IPSCs from both BLA- $(35 \pm 9 \%$ inhibition; $n=6)$ and NAc- $(38 \pm 4 \% ; n=11 ; p>0.05)$ projecting neurons (Fig. 5C).

\section{Opioid inhibition of somatodendritic DA release}

We hypothesized that KOR stimulation could inhibit stimulation-evoked somatodendritic release of DA. To test this, a train of five stimuli was used to evoke DA release that induced a slow IPSC (Beckstead et al., 2004) (Fig. 7). The IPSC was completely inhibited by the $\mathrm{D}_{2}$ receptor antagonist sulpiride (200 nM; data not shown). As predicted, the KOR agonist U69593 (200 nM) caused an inhibition of the IPSC (Fig. 7A). Although the mechanism of action was not investigated, we noted that the kinetics of the IPSC was not altered by U69593 (data not shown), supporting the hypothesis that the mechanism involves the reduction of DA release (Dalman and O’Malley, 1999; Chefer et al., 2005).

We next examined whether KORs would inhibit DA IPSCs recorded from BLA- and NAc-projecting neurons. We found that U69593 (200 nM) caused a greater inhibition of the IPSC in NAcprojecting DA neurons ( $52 \pm 7 \%$ inhibition; $n=8)$ than in BLA-projecting neurons ( $27 \pm 5 \%$ inhibition; $n=6 ; p<0.05$ ) (Fig. 7A). To determine whether the activation of M/DOR and $5-\mathrm{HT}_{1}$ receptors could also differentially regulate the DA IPSC, we examined the effects of ME ( $3 \mu \mathrm{M})$ and 5-CT (100 nM). However, in neither group of projecting neurons did ME or 5-CT inhibit the IPSC (Fig. $7 B, C$ ). Thus, whereas the $\mathrm{D}_{2}$ receptor IPSC in mesolimbic DA neurons appeared insensitive to M/DOR and $5-\mathrm{HT}_{1}$ agonists, the KOR agonist was able to inhibit this current.

\section{DA reuptake in the VTA}

In the guinea pig, DA uptake via dopamine uptake transporters (DATs) is more active in SNc neurons than in the VTA (Cragg et al., 1997). Because BLA-projecting neurons are located in the anterior/lateral VTA, whereas NAc-projecting neurons are located in the posterior/medial VTA (Fig. $1 C, D$ ), we used their separate locations to determine whether uptake of DA varied within the mouse VTA. Because DA is a substrate for all monoamine uptake transporters, the nonspecific uptake blocker cocaine $(1 \mu \mathrm{M})$ was used to determine the role of uptake within the VTA. Cocaine slowed the kinetics and increased the peak amplitude of the IPSC (Fig. 8A) (Beckstead et al., 2004) but had no differential effect on NAc- or BLA-projecting neurons (Fig. $8 B$ ). The kinetics and amplitude of the current induced by exog- 
enously applied DA (iontophoretic) were also altered by cocaine, but again, no differences were observed between NAc- and BLA-projecting neurons (Fig. 8A,B). Because the time course of the DA IPSC is strongly regulated by DATs (Beckstead et al., 2004) (but see Cragg et al., 2001), these results suggest that DA uptake is not different across the VTA. Examination of the 10-90\% IPSC rise time, the time to peak, and the IPSC half width also showed no differences between NAc- and BLA-projecting neurons (Fig. 8C).

\section{Discussion}

Identification and anatomical location of BLA- and NAc-projecting VTA

\section{DA neurons}

Dopaminergic projections from the VTA are organized into the mesolimbic and mesocortical systems, with the mesolimbic system sending major projections to both the BLA and the NAc (Albanese and Minciacchi, 1983; Le Moal and Simon, 1991; Brinley-Reed and McDonald, 1999; Hasue and Shammah-Lagnado, 2002). By using fluorescent microspheres as the retrograde tracer, we accurately identified only those VTA neurons that projected to these nuclei. Microspheres were chosen as the retrograde tracer, because unlike lipophillic tracers (e.g., DiI), they do not diffuse from the injection site and are only taken up at nerve terminals (Senatorov and $\mathrm{Hu}, 1998$; Senatorov and Renaud, 1999). This removed the possibility that neurons projecting to dorsal striatal structures (Maurin et al., 1999; Joel and Weiner, 2000) or passing through target areas were labeled. Thus, we ensured that only cells terminating in the BLA or NAc were labeled. BLA- and NAc-projecting VTA neurons occupied separate anatomical locations within the VTA. BLA-projecting neurons occurred in lateral/anterior locations, whereas NAc-projecting neurons were found in more medial/posterior areas. Both groups colocalized to $\mathrm{TH}(+)$ areas of the midbrain, medial to the MT (Fig. 1), confirming locations within the VTA. We found that the vast majority of mesolimbic VTA neurons in the mouse were DAergic. This contrasts with previous anatomical studies in the rat, which identified a substantial proportion of non-DAergic cells that send projections to these target areas (Swanson, 1982). Although the possibility exists that a species difference occurs, it may be that DAergic neurons are more likely to retrogradely transport microspheres to the VTA or that the soma of these cells are more easily identified.

Commonly, the presence of a large $I_{\mathrm{h}}$ is used to identify VTA DA neurons in in vitro electrophysiological studies. However, recent results suggest that not all VTA DA neurons exhibit a pronounced $I_{\mathrm{h}}$ (Neuhoff et al., 2002; Liss et al., 2005). We found that neither BLA- nor NAc-projecting VTA neurons exhibited as large of a current, as was found in more lateral SNc neurons (Fig. 2 ), confirming the study by Liss et al. (2005). The rank order of amplitudes appeared to approximately follow a lateral to medial

C 0.05. NLX, Naloxone.

\section{$D_{2}$ receptor IPSCs}

NAc projecting BLA projecting

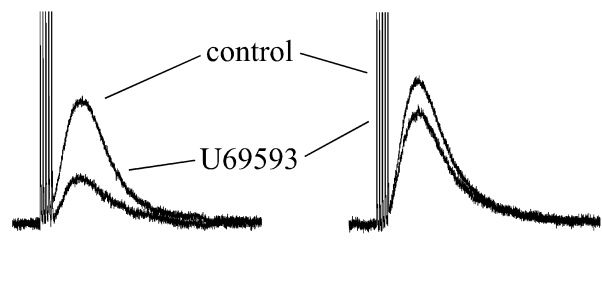

me $(\min )$
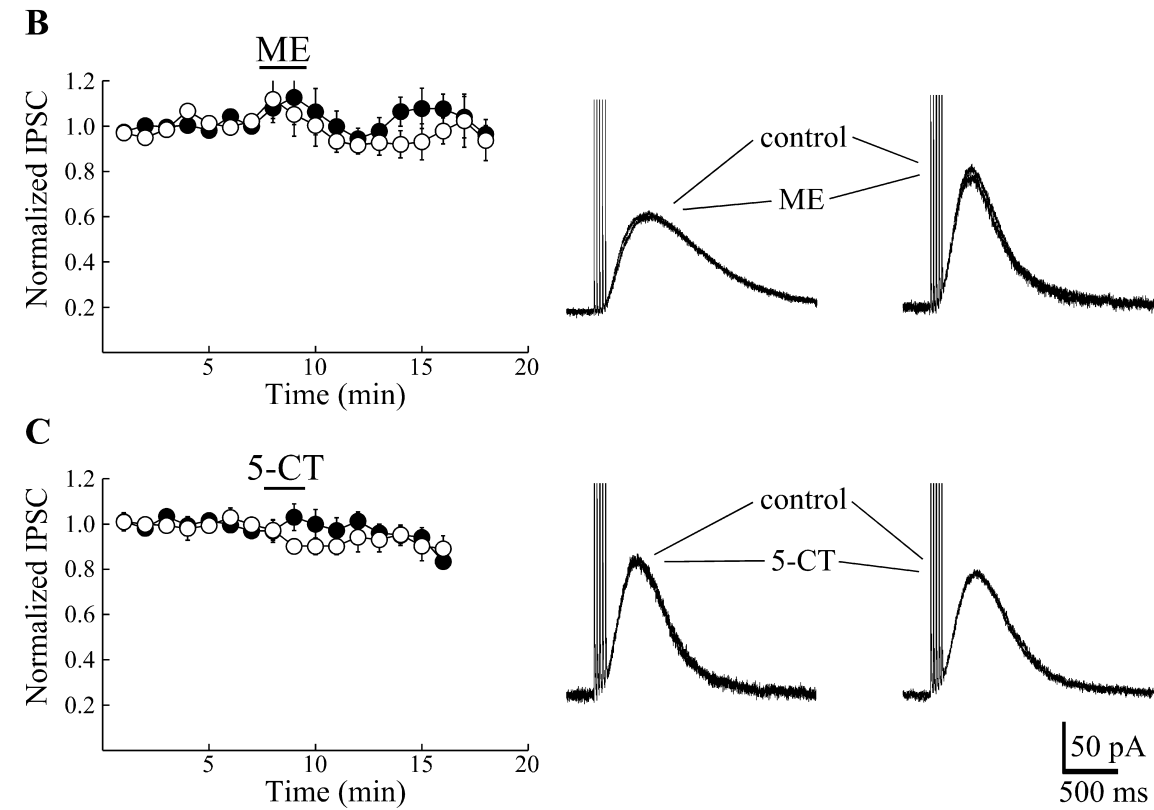

$\frac{50 \mathrm{pA}}{500 \mathrm{~ms}}$

Figure 7. Inhibition of the $D_{2}$ IPSC by KORs, but not M/DORs or 5-HT-Rs, is greater in NAC- than BLA-projecting VTA neurons. $\boldsymbol{A}-\boldsymbol{C}$, Normalized summary data and typical recordings of $\mathrm{D}_{2}$ IPSCs illustrating the effects of U69593 $(200 \mathrm{~nm} ; \boldsymbol{A}), \operatorname{ME}(3 \mu \mathrm{M} ; \boldsymbol{B})$, and

axis with $\mathrm{SNc}>\mathrm{BLA}$-projecting $>$ NAc-projecting neurons. These results suggest that the presence of a large $I_{\mathrm{h}}$ is an overall poor marker of mesolimbic projecting cells. Because $I_{\mathrm{h}}$ could not be used to identify labeled neurons as DA cells, the possibility existed that labeled projecting neurons were secondary GABAergic cells. To exclude this possibility, we relied on the presence of wide APs $(\geq 1.2 \mathrm{~ms}$ ), recorded in each neuron before gaining whole-cell access, to successfully identify cells as DAergic neurons. This property clearly distinguished DA neurons from secondary GABAergic neurons in our in vitro slice preparation (Fig. 3), suggesting that the majority of microsphere-labeled cells were DA neurons of the VTA.

\section{Effect of opioids on projecting VTA neurons}

Our results showed that opioid-induced inhibition of mesolimbic neurons depended on their target location. Of neurons projecting to the NAc, 94\% responded to the KOR agonist U69593, $37 \%$ responded to $\mathrm{M} / \mathrm{DOR}$ agonist $\mathrm{ME}$, whereas $0 \%$ responded to the $5-\mathrm{HT}_{1}$ agonist 5 -CT. In contrast, of neurons projecting to the BLA, $13 \%$ responded to $\mathrm{U} 69593,71 \%$ responded to $\mathrm{ME}$, and again $0 \%$ responded to 5-CT (Fig. 4). Neurons sensitive to KORs were more likely to project to the NAc than the BLA, whereas neurons sensitive to M/DORs were more likely to project to the 
A NAc projecting
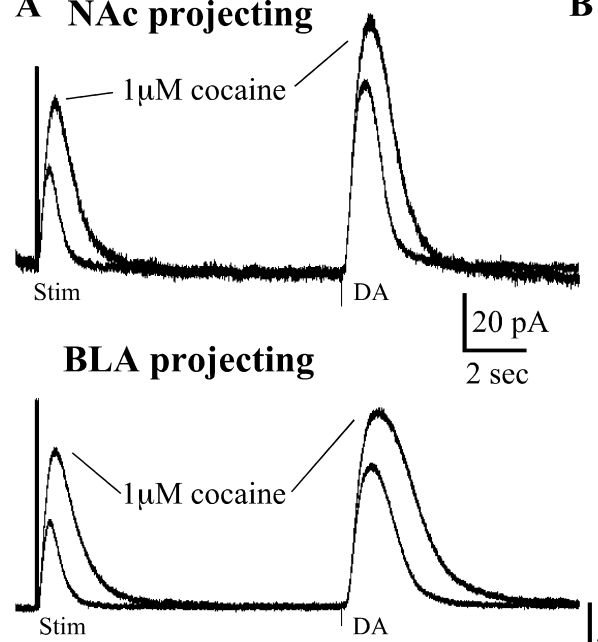

C

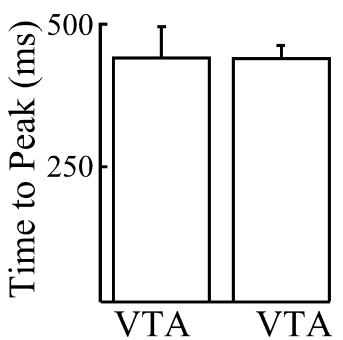

to NAc to BLA
B
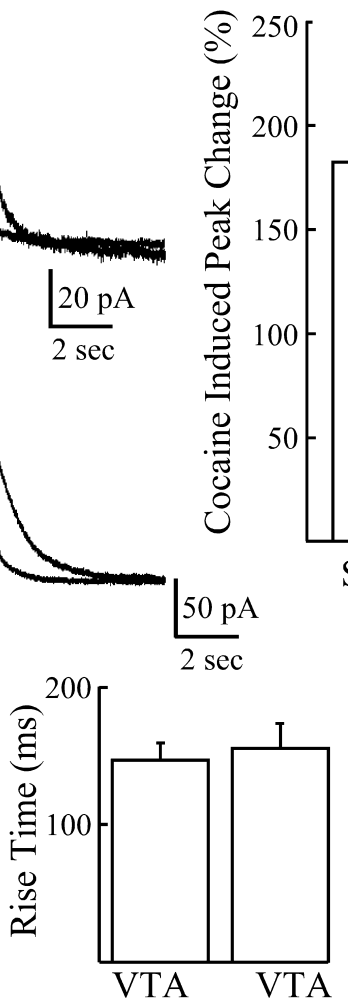

to NAc to BLA

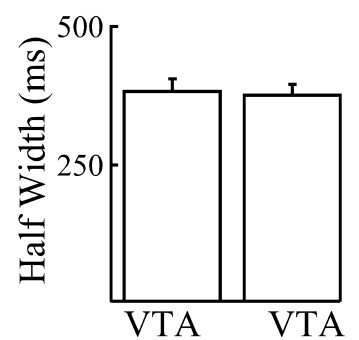

to NAc to BLA

Figure 8. Dopamine uptake transporters regulate extracellular dopamine equally at the somatodendritic level across the VTA. $A$, Representative synaptic and exogenous currents recorded from NAc- and BLA-projecting neurons. IPSCs were evoked with monopolar glass electrodes by a train of five pulses (duration, $0.5 \mathrm{~ms} ; 40 \mathrm{~Hz}$ ). Iontophoretic currents were evoked by ejecting DA as a cation with a single pulse ( $20-150 \mathrm{nA} ; 25-100 \mathrm{~ms})$ once every $60 \mathrm{~s}$. Note the equal increase in amplitudes and the slowing of kinetics of both currents by the application of the nonspecific monoamine uptake inhibitor cocaine (1 $\mu \mathrm{m})$ in both BLA- and NAc-projecting neurons. $\boldsymbol{B}$, Summary data (normalized percentage change; mean \pm SEM) from BLA- $(n=5)$ and NAc- $(n=7)$ projecting neurons. $C$, Summary of the kinetics of $D_{2}$ IPSCs recorded in BLA- $(n=6)$ and NAC- $(n=9)$ projecting VTA neurons. Stim, Stimulation.

BLA than the NAc. Because ME can activate both MORs and DORs, the possibility exists that the actions of ME is through DORs on some neurons and MORs on others. DA neurons that are sensitive to MORs are classified as tertiary cells (Williams et al., 2001). This class of neurons in the guinea pig was distinguished based on the sensitivity to 5-HT. Electrical stimulation also resulted in an IPSP that was mediated by 5-HT (Cameron et al., 1997). Surprisingly, neither the bath application of the 5-CT (Fig. 4E) nor stimulation (data not shown) induced a 5-HTmediated IPSC in either BLA- or NAc-projecting neurons. This rules out the possibility that these cells were tertiary neurons. Immunohistochemical examination of projecting cells that responded to ME showed that $>80 \%$ were DAergic. It is not known whether this represents a species difference, a lack of tertiary cells projecting to either the BLA or the NAc, or whether it is primarily principle $\mathrm{TH}(+)$ neurons that become tracer labeled.

\section{Regulation of GABAergic transmission between populations of mesolimbic neurons}

The release of GABA within the VTA is acutely inhibited by opioids and is chronically altered during the withdrawal from chronic opioid use (Williams et al., 2001). We found that, like the differential postsynaptic effects of U69593, GABAergic transmission was unequally inhibited by the KOR agonist. U69593 caused a greater inhibition of $\mathrm{GABA}_{\mathrm{A}}$ IPSCs recorded from DA neurons projecting to the BLA. In contrast, U69593 caused a greater inhibition of $\mathrm{GABA}_{\mathrm{B}}$ IPSCs recorded from DA neurons projecting to the NAc (Figs. $5 A, 6 A)$. This finding further confirms that DA neurons projecting to separate mesolimbic targets possess different composition of opioid receptors. Through the course of these experiments, we found that in addition to inhibiting $\mathrm{GABA}_{\mathrm{B}}$ IPSCs, $5-\mathrm{HT}_{1}$-receptors also inhibited $\mathrm{GABA}_{\mathrm{A}}$ IPSCs (Fig. 6C). This is opposite to the rat, in which 5-HT inhibits the $\mathrm{GABA}_{\mathrm{B}}$, but not the $\mathrm{GABA}_{\mathrm{A}}$, IPSP (Sugita et al., 1992). Whether this is a property of mesolimbic neurons or a species difference is not clear.

\section{Inhibition of the $\mathrm{D}_{2}$ IPSC by KORs}

Both M/DOR and KOR agonists evoked different amplitudes of inhibitory outward currents in BLA- and NAc-projecting neurons (Fig. 4). These opioid-induced currents result from the activation of GIRK channels, which hyperpolarize the cell membrane and lead to reduced firing rates and activity (Williams et al., 2001; Margolis et al., 2003). The DA IPSC is believed to result from the somatodendritic release of DA from neighboring neurons (Geffen et al., 1976; Kalivas and Duffy, 1991; Cragg et al., 2001; Beckstead et al., 2004). We reasoned that the opioid-induced inhibition recorded in individual projecting neurons implied a local reduction in the overall activity of DA neurons within that area. This reduction in activity would result in decreased somatodendritic DA release. If this were the case, regions exhibiting greater opioid induced whole-cell currents would also exhibit greater opioid-induced inhibition of the DA IPSC. Thus, we hypothesized that U69593 would cause a greater inhibition of the DA IPSC in NAc-projecting neurons, whereas ME would cause a greater inhibition of the IPSC in BLA-projecting cells (Fig. 4). As predicted, activation of KORs led to a greater inhibition of the DA IPSC in NAc-projecting neurons (Fig. 7A). The effect of M/DOR activation, however, was not as predicted. Although the M/DOR agonist ME inhibited $13 \%$ of NAc- and $71 \%$ of BLA-projecting neurons (Fig. 4), it had no effect on the $\mathrm{D}_{2}$ IPSC (Fig. 7A). Two possibilities exist to explain the lack of effect of M/DOR stimulation. First, the ME-induced local hyperpolarization of DA neurons may have been insufficient to significantly reduce presynaptic firing. Alternatively, the lack of effect of ME on the DA IPSC may be attributable to MORs failing to couple to the machinery regulating the release of $\mathrm{DA}$.

\section{Dopamine uptake transporters are equally distributed across} the mouse VTA

The major mechanism terminating DA signaling is uptake by DAT (Adell and Artigas, 2004). We set out to determine whether DA uptake was similar between two populations of mesolimbic neurons. Termination of the DA IPSC is strongly regulated by DA reuptake (Beckstead et al., 2004), suggesting that if differences in 
DAT levels occurred, altered kinetics of the IPSC would be observed. This was not the case (Fig. 8). Furthermore, the nonspecific monoamine inhibitor cocaine potentiated both the IPSC and iontophoretic current to similar extents in both BLA- and NAc-projecting neurons (Fig. 8). Given that $\mathrm{D}_{2}$ receptors and dopamine transporters interact to regulate extracellular DA levels (Schmitz et al., 2002), our findings suggest that, at the somatodendritic level, the regulation of DA is tightly regulated to the same extent across the mesolimbic system of the VTA.

\section{Conclusions}

The mesolimbic DA system mediates the stimulating and rewarding properties of nearly all drugs of abuse (Koob, 1992; White, 1996; Wise, 1996a,b; Williams et al., 2001). By recording from identified neurons that projected from the VTA to the BLA and the NAc, we have been able to demonstrate that significant physiological differences occurred between different populations of VTA DA neurons. This suggests that DA neurons of the VTA are not a homogenous population of cells but vary in several respects. Opioid inhibition of dopamine neurons varied with target location, which suggests that the behavioral effects of opioids may be the result of inhibition of distinct subpopulations of mesolimbic neurons. These findings provide insight into potential important therapeutic targets for certain motivated behaviors including drug addiction and provide a better understanding for the role of specific signaling between different brain regions.

\section{References}

Adell A, Artigas F (2004) The somatodendritic release of dopamine in the ventral tegmental area and its regulation by afferent transmitter systems. Neurosci Biobehav Rev 28:415-431.

Albanese A, Minciacchi D (1983) Organization of the ascending projections from the ventral tegmental area: a multiple fluorescent retrograde tracer study in the rat. J Comp Neurol 216:406-420.

Bachtell RK, Whisler K, Karanian D, Self DW (2005) Effects of intranucleus accumbens shell administration of dopamine agonists and antagonists on cocaine-taking and cocaine-seeking behaviors in the rat. Psychopharmacology (Berl) 183:41-53.

Bals-Kubik R, Ableitner A, Herz A, Shippenberg TS (1993) Neuroanatomical sites mediating the motivational effects of opioids as mapped by the conditioned place preference paradigm in rats. J Pharmacol Exp Ther 264:489-495.

Beckstead MJ, Grandy DK, Wickman K, Williams JT (2004) Vesicular dopamine release elicits an inhibitory postsynaptic current in midbrain dopamine neurons. Neuron 42:939-946.

Bonci A, Williams JT (1997) Increased probability of GABA release during withdrawal from morphine. J Neurosci 17:796-803.

Brinley-Reed M, McDonald AJ (1999) Evidence that dopaminergic axons provide a dense innervation of specific neuronal subpopulations in the rat basolateral amygdala. Brain Res 850:127-135.

Cameron DL, Williams JT (1993) Dopamine D1 receptors facilitate transmitter release. Nature 366:344-347.

Cameron DL, Wessendorf MW, Williams JT (1997) A subset of ventral tegmental area neurons is inhibited by dopamine, 5 -hydroxytryptamine and opioids. Neuroscience 77:155-166.

Chefer VI, Czyzyk T, Bolan EA, Moron J, Pintar JE, Shippenberg TS (2005) Endogenous $\kappa$-opioid receptor systems regulate mesoaccumbal dopamine dynamics and vulnerability to cocaine. J Neurosci 25:5029-5037.

Cragg S, Rice ME, Greenfield SA (1997) Heterogeneity of electrically evoked dopamine release and reuptake in substantia nigra, ventral tegmental area, and striatum. J Neurophysiol 77:863-873.

Cragg SJ, Nicholson C, Kume-Kick J, Tao L, Rice ME (2001) Dopaminemediated volume transmission in midbrain is regulated by distinct extracellular geometry and uptake. J Neurophysiol 85:1761-1771.

Dalman FC, O’Malley KL (1999) Kappa-opioid tolerance and dependence in cultures of dopaminergic midbrain neurons. J Neurosci 19: $5750-5757$.
Dodt HU, Eder M, Schierloh A, Zieglgansberger W (2002) Infrared-guided laser stimulation of neurons in brain slices. Sci STKE 2002:PL2.

Everitt BJ, Dickinson A, Robbins TW (2001) The neuropsychological basis of addictive behaviour. Brain Res Brain Res Rev 36:129-138.

Frenois F, Stinus L, Di Blasi F, Cador M, Le Moine C (2005) A specific limbic circuit underlies opiate withdrawal memories. J Neurosci 25:1366-1374.

Garzon M, Pickel VM (2001) Plasmalemmal mu-opioid receptor distribution mainly in nondopaminergic neurons in the rat ventral tegmental area. Synapse 41:311-328.

Geffen LB, Jessell TM, Cuello AC, Iversen LL (1976) Release of dopamine from dendrites in rat substantia nigra. Nature 260:258-260.

Grace AA, Onn SP (1989) Morphology and electrophysiological properties of immunocytochemically identified rat dopamine neurons recorded in vitro. J Neurosci 9:3463-3481.

Gysling K, Wang RY (1983) Morphine-induced activation of A10 dopamine neurons in the rat. Brain Res 277:119-127.

Hasue RH, Shammah-Lagnado SJ (2002) Origin of the dopaminergic innervation of the central extended amygdala and accumbens shell: a combined retrograde tracing and immunohistochemical study in the rat. J Comp Neurol 454:15-33.

Hatfield T, Han JS, Conley M, Gallagher M, Holland P (1996) Neurotoxic lesions of basolateral, but not central, amygdala interfere with pavlovian second-order conditioning and reinforcer devaluation effects. J Neurosci 16:5256-5265.

Ikemoto S, Panksepp J (1999) The role of nucleus accumbens dopamine in motivated behavior: a unifying interpretation with special reference to reward-seeking. Brain Res Brain Res Rev 31:6-41.

Joel D, Weiner I (2000) The connections of the dopaminergic system with the striatum in rats and primates: an analysis with respect to the functional and compartmental organization of the striatum. Neuroscience 96:451-474.

Johnson SW, North RA (1992a) Opioids excite dopamine neurons by hyperpolarization of local interneurons. J Neurosci 12:483-488.

Johnson SW, North RA (1992b) Two types of neurone in the rat ventral tegmental area and their synaptic inputs. J Physiol (Lond) 450:455-468.

Johnson SW, Mercuri NB, North RA (1992) 5-Hydroxytryptamine1B receptors block the $\mathrm{GABA}_{\mathrm{B}}$ synaptic potential in rat dopamine neurons. J Neurosci 12:2000-2006.

Kalivas PW, Duffy P (1991) A comparison of axonal and somatodendritic dopamine release using in vivo dialysis. J Neurochem 56:961-967.

Koob GF (1992) Drugs of abuse: anatomy, pharmacology and function of reward pathways. Trends Pharmacol Sci 13:177-184.

Le Moal M, Simon H (1991) Mesocorticolimbic dopaminergic network: functional and regulatory roles. Physiol Rev 71:155-234.

Liss B, Haeckel O, Wildmann J, Miki T, Seino S, Roeper J (2005) K-ATP channels promote the differential degeneration of dopaminergic midbrain neurons. Nat Neurosci 8:1742-1751.

Margolis EB, Hjelmstad GO, Bonci A, Fields HL (2003) $\kappa$-Opioid agonists directly inhibit midbrain dopaminergic neurons. J Neurosci 23:9981-9986.

Maurin Y, Banrezes B, Menetrey A, Mailly P, Deniau JM (1999) Threedimensional distribution of nigrostriatal neurons in the rat: relation to the topography of striatonigral projections. Neuroscience 91:891-909.

Neuhoff H, Neu A, Liss B, Roeper J (2002) $I_{\mathrm{h}}$ channels contribute to the different functional properties of identified dopaminergic subpopulations in the midbrain. J Neurosci 22:1290-1302.

Pan ZZ (1998) mu-Opposing actions of the kappa-opioid receptor. Trends Pharmacol Sci 19:94-98.

Paxinos G, Franklin KBJ (2001) The mouse brain in stereotaxic coordinates, Ed 2. Orlando, FL: Academic.

Phillips AG, LePiane FG (1980) Reinforcing effects of morphine microinjection into the ventral tegmental area. Pharmacol Biochem Behav 12:965-968.

Schmitz Y, Schmauss C, Sulzer D (2002) Altered dopamine release and uptake kinetics in mice lacking $\mathrm{D}_{2}$ receptors. J Neurosci 22:8002-8009.

See RE, Kruzich PJ, Grimm JW (2001) Dopamine, but not glutamate, receptor blockade in the basolateral amygdala attenuates conditioned reward in a rat model of relapse to cocaine-seeking behavior. Psychopharmacology (Berl) 154:301-310.

Senatorov VV, Hu B (1998) Unidirectional axonal transport in in vitro adult rat brain explants. Neuroscience 82:59-67.

Senatorov VV, Renaud LP (1999) Projections of medullary and pontine 
noradrenergic neurons to the horizontal limb of the nucleus of diagonal band in the rat. Neuroscience 88:939-947.

Shoji Y, Delfs J, Williams JT (1999) Presynaptic inhibition of $\mathrm{GABA}_{\mathrm{B}}$ mediated synaptic potentials in the ventral tegmental area during morphine withdrawal. J Neurosci 19:2347-2355.

Sugita S, Johnson SW, North RA (1992) Synaptic inputs to GABAA and GABAB receptors originate from discrete afferent neurons. Neurosci Lett 134:207-211.

Swanson LW (1982) The projections of the ventral tegmental area and adjacent regions: a combined fluorescent retrograde tracer and immunofluorescence study in the rat. Brain Res Bull 9:321-353.

Ungless MA, Magill PJ, Bolam JP (2004) Uniform inhibition of dopamine neurons in the ventral tegmental area by aversive stimuli. Science 303:2040-2042.
White FJ (1996) Synaptic regulation of mesocorticolimbic dopamine neurons. Annu Rev Neurosci 19:405-436.

Whitelaw RB, Markou A, Robbins TW, Everitt BJ (1996) Excitotoxic lesions of the basolateral amygdala impair the acquisition of cocaine-seeking behaviour under a second-order schedule of reinforcement. Psychopharmacology (Berl) 127:213-224.

Williams JT, North RA, Shefner SA, Nishi S, Egan TM (1984) Membrane properties of rat locus coeruleus neurones. Neuroscience 13:137-156.

Williams JT, Christie MJ, Manzoni O (2001) Cellular and synaptic adaptations mediating opioid dependence. Physiol Rev 81:299-343.

Wise RA (1996a) Addictive drugs and brain stimulation reward. Annu Rev Neurosci 19:319-340.

Wise RA (1996b) Neurobiology of addiction. Curr Opin Neurobiol 6:243251. 